\title{
NUMERICAL SIMULATION OF INVESTMENT CASTING PROCESS OF NICKEL-BASED ALLOY.
}

\author{
O. BEN LENDA ${ }^{1 *}$, A. TARA ${ }^{2}$, O. JBARA ${ }^{2}$ and E. SAAD ${ }^{1}$.
}

\section{Laboratory of Physical-Chemistry of Processes and Materials, Hassan $1^{\text {st }}$ University, Faculty of Sciences and Technology Settat, Settat, Morocco (*o.benlenda@uhp.ac.ma)}

2. Laboratory of Engineering and Materials Science, University of Reims Champagne-Ardenne, Reims, France.

\begin{abstract}
In this paper, we elaborated the nickel-based alloy type Hastelloy G30 and we analyzed it by techniques of characterization in order to interpret the results obtained through a computer simulation. The calculation of the thermo-physical properties of the alloy and the simulation of filling and solidification of the casting was performed by the software ProCAST. The validation of the numerical results was done by the following experimental techniques: optical microscopy and hardness test. In the center of the elaborate piece, the experimental results showed the appearance of porosity and leading to embrittlement of the alloy. According to the numerical simulation, this is caused by a fraction of the liquid that remains trapped in this area.
\end{abstract}

Keywords: Hastelloy G30, ProCAST, Optical microscopy, Porosity, Solidification, Investment casting.

\section{Introduction}

The Nickel-based superalloys have been developed to combine improved properties at elevated temperatures. [1]. Hastelloy G30 is used in the service of the nitric acid, that of the phosphoric acid and petrochemical applications [2].

Several physical phenomena influence the process of solidification of the casting of the alloy [3]. The quality of alloys is commonly affected by various internal defects. Among these defects, we cite the porosity which is a very difficult defect to remove by subsequent thermomechanical treatments [4].

For a long time, the formation of microporosity has been the subject of many studies [5, 6]. Works on the prediction of porosity of nickel-based superalloys is limited compared to those done on aluminum-based alloys and steels $[7,8]$. The interest of predicting the formation of defects in the investment casting of the nickel-based superalloys was renewed at the end of the second millennium [9-12].

The aim of this work to elaborate Hastelloy G30, to analyze it by some techniques of characterization and to interpret the results obtained through a simulation of its solidification.

\section{Materials and methods}

\subsection{Materials}

The investment casting was used to manufacture the nickel-based alloy type Hastelloy G30. The alloy elaborate has the form of a plate and the mold is made of the steel H13. The dimensions of the plate are: $350 \mathrm{~mm}$ in width, $470 \mathrm{~mm}$ in length, $25 \mathrm{~mm}$ in thickness.

Hastelloy G30 was prepared from high purity metals $(99.9 \%)$. The nickel and the alloying elements are melted in an electric resistance furnace under an inert atmosphere and subsequently poured into the mold. The chemical composition of Hastelloy G30 is shown in table 1 [13].

Table 1: Chemical composition of Hastelloy G30.

\begin{tabular}{|c|c|c|c|c|c|c|c|}
\hline $\mathrm{Ni}$ & $\mathrm{Cr}$ & $\mathrm{Mo}$ & $\mathrm{C}$ & $\mathrm{Fe}$ & $\mathrm{Co}$ & $\mathrm{Cu}$ & Others \\
\hline Balance & 30 & 5 & 0.03 & 15 & 5 & 2 & $\mathrm{Nb}+\mathrm{Ta}$ \\
\hline
\end{tabular}

\subsection{Procedure of simulation}

The calculation of the thermo-physical properties, the mesh and the simulation of filling and solidification of the casting was carried out by the software ProCAST. The parameters used in the simulation are: filing time of 10 seconds, casting temperature of $1320{ }^{\circ} \mathrm{C}$ and preheating temperature of the mold of $1000{ }^{\circ} \mathrm{C}$.

\subsection{Microscopic study}

The structure of the samples was observed by optical microscopy. The metallographer used is Optika $\mathrm{B}-383 \mathrm{MET}$ type. The etchant used is aqua regia and the immersion time is between 5 and 60 seconds [13].

\subsection{Hardness measurement :}

Hardness tests are performed using a durometer WILSON type. Rockwell C hardness (HRC) scale is used and each measurement is the average of several measurements.

\section{Results and discussions}




\subsection{Numerical results of filling and solidification of Hastelloy G30}

The Figure 1 shows the filling system, the riser and the alloy mesh generated by Mesh-Cast (ProCAST software package). The filling system is lateral, constituting of a sprue, a runner and a gate. The riser is located at the top of the casting. We performed a tetrahedral mesh, with a distance between two nodes of $2 \mathrm{~mm}$ which allowed to have a finite element model consisting of 181200 nodes and 860250 elements. We chose a mesh density in order to have precise results, and to reduce the computation time as much as possible.

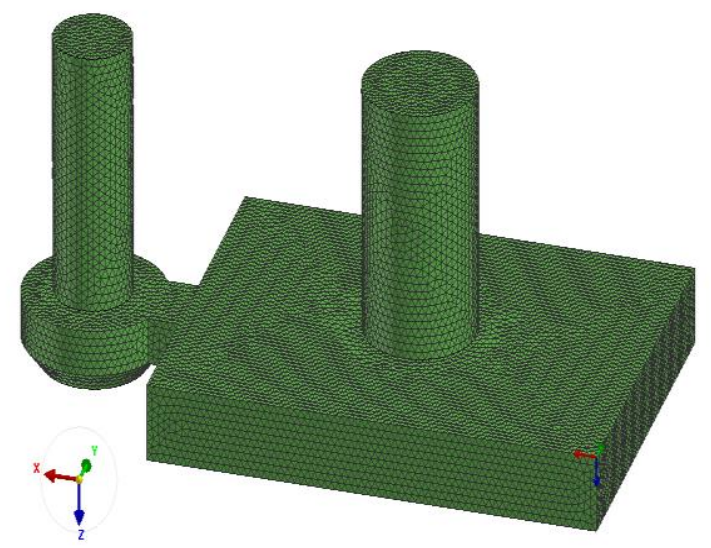

Figure 1 : Mesh of the filling system, the riser and the alloy.

The figure 2 shows the distribution of the temperature of the plate during the cooling at ambient temperature by the air. According to this figure, the lines of the contours of the temperature field appear in the form of concentrated circles. We noted that we have a maximum of temperature at the center of the alloy; this temperature is higher than the liquidus while the temperature at the corners is lower than the solidus.

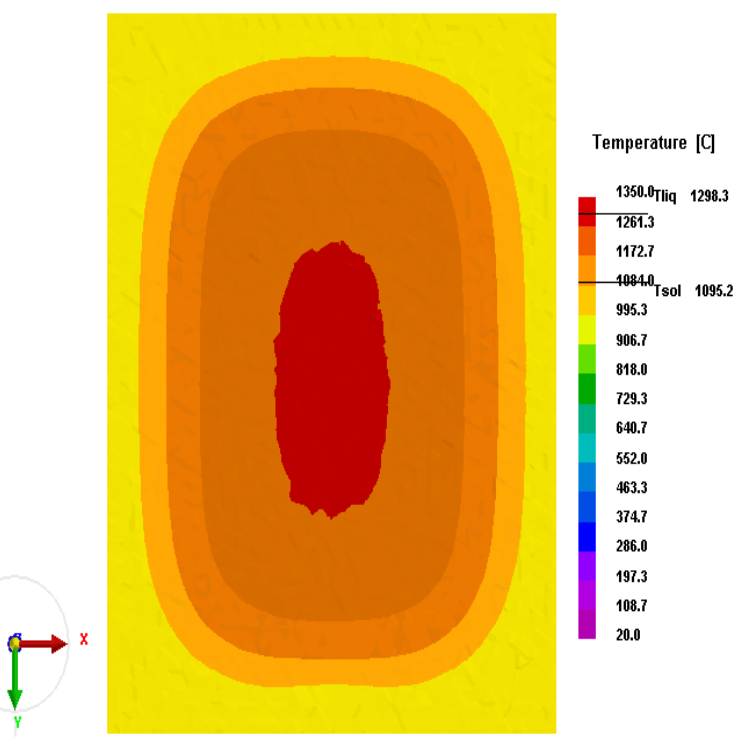

Figure 2 : The temperature field of the plate after 13 seconds.
The figure 3 shows the distribution of the solidified fraction of the alloy during the cooling. We noted that during the solidification, a fraction of the liquid is trapped in the center of the alloy.

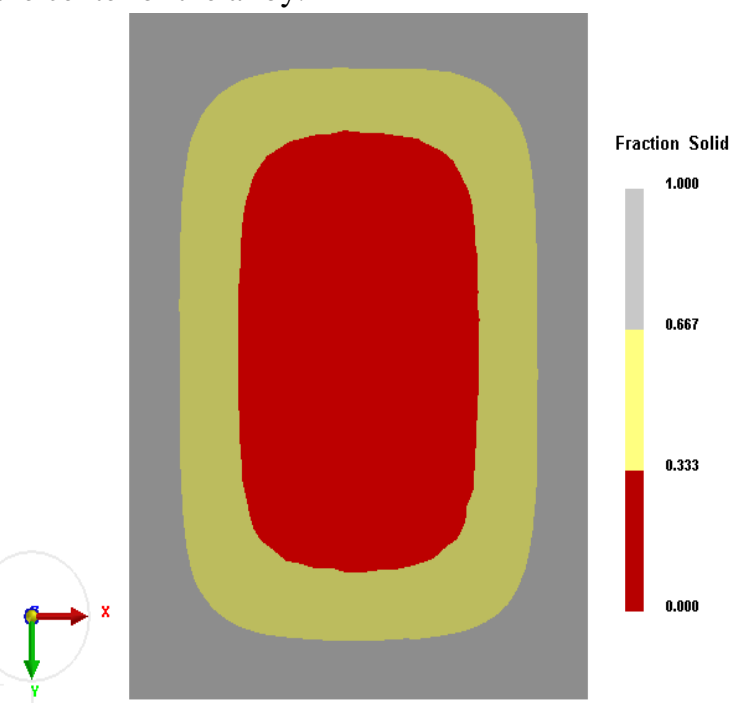

Figure 3 : The fraction of solid of the plate after 14 seconds.

The figure 4 shows the prediction of the porosity after a complete cooling of the plate. We observed that the predicted porosity in the center of the plate is between 0.44 and $1.78 \%$, while the rest of the plate is non-porous. These results indicate that microporosity defects are formed at the end of the solidification sequence due to the formation of liquid island at the center of the plate. The liquid islands form the potential defects since no liquid feeding metal can be introduced into these areas during the process of solidification [14].

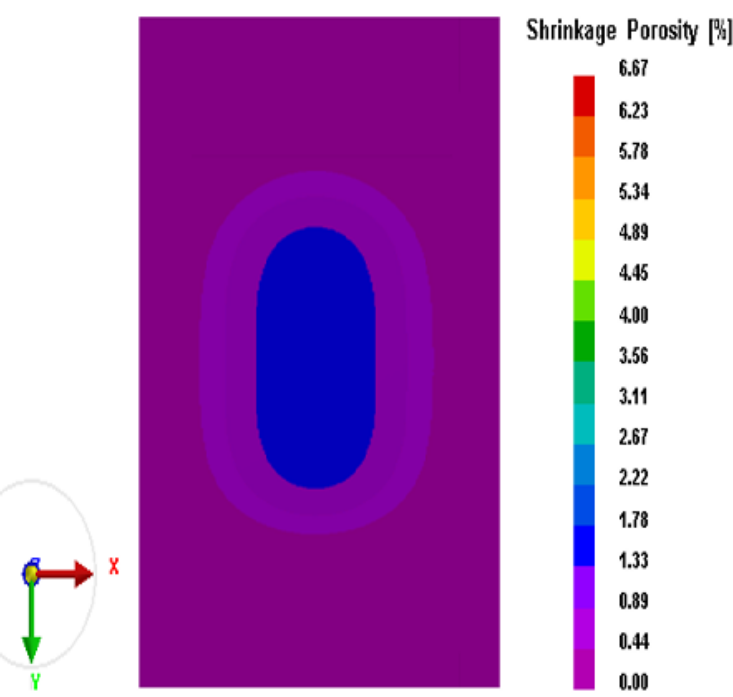

Figure 4: The porosity of the plate after solidification.

\subsection{Microscopic study}

The figure 5 shows the micrographs of different areas of the alloy. The images obtained by optical microscopy were in agreement with the results found by simulation. 
We observed the appearance of pores with an average size of $2 \mu \mathrm{m}$ in the center of the plate. The microporosity defects in the casting are distributed as separated and dispersed pores. In other areas, we saw just the matrix and a small amount of the carbides. In the four corners of the plate, the microstructure is free of microporosity defects.

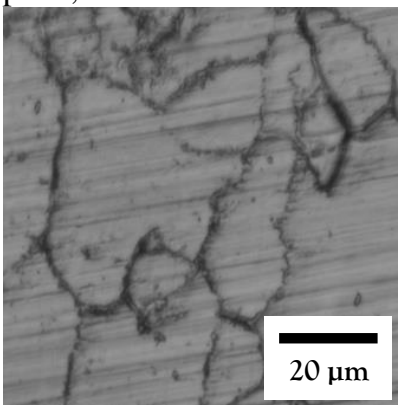

(a)

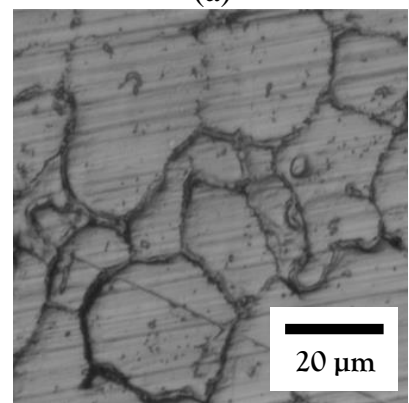

(c)

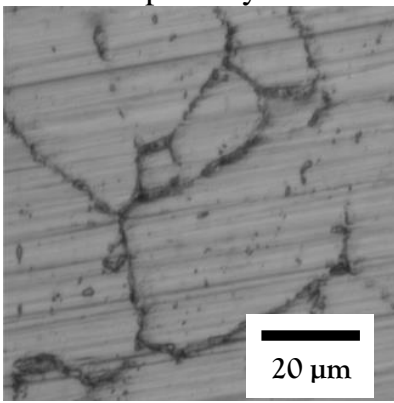

(b)

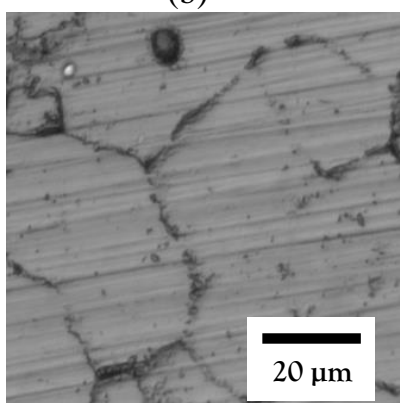

(d)

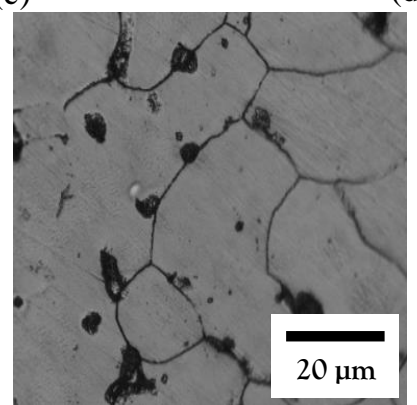

(e)

Figure 5: Micrographs of Hastelloy G30.

a) top right, b) top left, c) bottom right, d) bottom left and e) center.

\subsection{Hardness measurement}

We measured the hardness of Hastelloy G30 in the four corners and in the center after the solidification. We have noticed, a hardness of $32 \mathrm{HRC}$ at the four corners, it is higher than the center of the alloy which is $29 \mathrm{HRC}$

According to the microscopic study, the microstructure is compact at the four corners of the plate, unlike the middle of the casting where a quantity of pores is observed. These defects lead to a significant loss of the hardness of the nickel-based alloy.

\section{Conclusions}

In this work, we performed a numerical and an experimental study of the filling and the solidification of Hastelloy G30. After the casting, the optical microscopy revealed the presence of pores in the center of the alloy where a decrease in hardness was noted compared to the ends of the plate. The numerical results showed that a fraction of the liquid is trapped in the center of the plate during the cooling. Therefore, the solidification of Hastelloy G30 is done with a non-uniform manner and that leads to a porosity defect which negatively influence the quality of the alloy.

\section{References}

[1] F. Cardarelli, Materials Handbook: A Concise Desktop Reference, Second edition, SpringerVerlag, London, 2008.

[2] ASM International Handbook Committee, Nickel, Cobalt and Their Alloys, Materials Park $\mathrm{OH}$ : ASM International, United States of America, 2000.

[3] ASM International Handbook Committee, Casting Design and Performance, Materials Park OH: ASM International, United States of America, 2009.

[4] D. Mackie, Characterization of casting defects in DC cast magnesium alloys, Thesis, University of Manchester, 2013.

[5] J. Campbell, On the origin of porosity in long freezing-range alloys, Brit. Foundrym., 62 (1969), 147-158.

[6] W.S. Pellini, Factors which determine riser adequacy and feeding range, AFS Trans., 61 (1953), 61-80.

[7] D.M. Stefanescu, Computer simulation of shrinkage related defects in metal castings-a review, Inter. J. Cast. Metal. Res., 18 (2005), 129-143.

[8] P.D. Lee, A. Chirazi, D. See, Modeling microporosity in aluminum-silicon alloys: $a$ review, J. Light Metals, 1 (2001), 15-30.

[9] K.O. Yu, M.J. Beffel, M. Robinson, D.D. Goettsch, B.G. Thomas, D. Pinella, R.G. Carlson, Solidification modeling of singlecrystal investment castings, AFS Trans., 98 (1990), 417- 422.

[10] K.O. Yu, J.J. Nichols, M. Robinson, Finiteelement thermal modeling of casting microstructures and defects, JOM, 44 (1992), 21 -25 .

[11] A.L. Purvis, C.R. Hanslits, R.S. Diehm, Modeling characteristics for solidification in single-crystal, investment-cast superalloys, JOM, 46 (1994), 38 - 41.

[12] T.M. Pollock, W.H. Murphy, The breakdown of single-crystal solidification in high refractory nickel-base alloys, Metall. Mater. Trans. A, 27A (1996), 1081- 1094.

[13] ASM International Handbook Committee, ASM Handbook: Volume 9: Metallography and Microstructures, Materials Park OH: ASM International, United States of America, 2004

[14] Y. Fang, J. Hu, J. Zhou, Y. Yu, Numerical simulation of filling and solidification in exhaust manifold investment casting, Int. J. Metalcast., 8 (2014), 39-45. 